\title{
ORIGINAL ARTICLE Body fat mass and the proportion of very large adipocytes in pregnant women are associated with gestational insulin resistance
}

\author{
H Svensson ${ }^{1}$, L Wetterling ${ }^{1}$, M Bosaeus ${ }^{2}$, B Odén ${ }^{1}$, A Odén ${ }^{3}$, E Jennische ${ }^{4}$, S Edén ${ }^{5}$, A Holmäng ${ }^{2}$ and M Lönn ${ }^{1}$
}

BACKGROUND/OBJECTIVES: Pregnancy is accompanied by fat gain and insulin resistance. Changes in adipose tissue morphology and function during pregnancy and factors contributing to gestational insulin resistance are incompletely known. We sought to characterize adipose tissue in trimesters 1 and 3 (T1/T3) in normal weight (NW) and obese pregnant women, and identify adipose tissue-related factors associated with gestational insulin resistance.

SUBJECTS/METHODS: Twenty-two NW and 11 obese women were recruited early in pregnancy for the Pregnancy Obesity Nutrition and Child Health study. Examinations and sampling of blood and abdominal adipose tissue were performed longitudinally in T1/T3 to determine fat mass (air-displacement plethysmography); insulin resistance (homeostasis model assessment of insulin resistance, HOMA-IR); size, number and lipolytic activity of adipocytes; and adipokine release and density of immune cells and blood vessels in adipose tissue.

RESULTS: Fat mass and HOMA-IR increased similarly between T1 and T3 in the groups; all remained normoglycemic. Adipocyte size increased in NW women. Adipocyte number was not influenced, but proportions of small and large adipocytes changed oppositely in the groups. Lipolytic activity and circulating adipocyte fatty acid-binding protein increased in both groups. Adiponectin release was reduced in NW women. Fat mass and the proportion of very large adipocytes were most strongly associated with T3 HOMA-IR by multivariable linear regression $\left(R^{2}=0.751, P<0.001\right)$.

CONCLUSIONS: During pregnancy, adipose tissue morphology and function change comprehensively. NW women accumulated fat in existing adipocytes, accompanied by reduced adiponectin release. In comparison with the NW group, obese women had signs of adipocyte recruitment and maintained adiponectin levels. Body fat and large adipocytes may contribute significantly to gestational insulin resistance.

International Journal of Obesity (2016) 40, 646-653; doi:10.1038/ijo.2015.232

\section{INTRODUCTION}

Insulin resistance is a characteristic of normal glycemic physiology during pregnancy and of type 2 diabetes and gestational diabetes mellitus. ${ }^{1,2}$ Maternal metabolism changes substantially during pregnancy to meet feto-placental and maternal demands. These metabolic changes may be accentuated in women who develop gestational diabetes mellitus. ${ }^{2}$ Although the mechanisms are not fully understood, gestational insulin resistance has been attributed to insulin-desensitizing effects of placental hormones, mainly placental growth hormone, ${ }^{3}$ and increased maternal adiposity. ${ }^{4}$ Both prepregnancy body mass index (BMI) and weight gain during pregnancy are positively associated with gestational insulin resistance, ${ }^{5-7}$ and obesity is a risk factor for gestational diabetes mellitus. ${ }^{8}$

Despite the impact of body weight and obesity on gestational insulin resistance, there are few studies of human adipose tissue morphology and function during pregnancy, in particular longitudinal observations. Studies of adipocytes from women in different trimesters revealed changes in lipolytic activity that promote maternal fat accumulation in early pregnancy and enhance fat mobilization in late pregnancy. ${ }^{9}$ Longitudinally during pregnancy, adipose tissue and the placenta also contribute to modified circulating levels of adipokines. ${ }^{10}$ Only two longitudinal studies addressed human adipose tissue cellularity during pregnancy. ${ }^{11,12}$ Biopsies of gluteal adipose tissue revealed larger, ${ }^{11,12}$ more numerous ${ }^{12}$ adipocytes in normal weight (NW) women late in pregnancy than before or early in pregnancy. It is not known if these findings are relevant also to other depots and to women entering pregnancy obese. The abdominal subcutaneous depot is of interest because most of the fat retained during healthy pregnancy is stored subcutaneously on the trunk, as determined by magnetic resonance imaging. ${ }^{13}$

In this study, we obtained subcutaneous abdominal adipose tissue from NW and obese pregnant women in trimester (T) 1 and T3. Our aim was to longitudinally characterize adipokine release, the density of immune cells and blood vessels, and size, number and lipolytic activity of adipocytes. We also aimed to identify, among these characteristics, factors associated with gestational insulin resistance.

${ }^{1}$ Department of Clinical Chemistry and Transfusion Medicine, Sahlgrenska Academy, University of Gothenburg, Gothenburg, Sweden; ${ }^{2}$ Department of Physiology, Institute of Neuroscience and Physiology, Sahlgrenska Academy, University of Gothenburg, Gothenburg, Sweden; ${ }^{3}$ Department of Mathematical Sciences, Chalmers University of Technology, Gothenburg, Sweden; ${ }^{4}$ Department of Medical Biochemistry and Cell Biology, Institute of Biomedicine, Sahlgrenska Academy, University of Gothenburg, Gothenburg, Sweden and ${ }^{5}$ Department of Internal Medicine, Institute of Medicine, Sahlgrenska Academy, University of Gothenburg, Gothenburg, Sweden. Correspondence: Dr H Svensson, Department of Clinical Chemistry, Sahlgrenska University Hospital, Bruna Stråket 16, Gothenburg S-413 45, Sweden. 


\section{SUBJECTS AND METHODS}

Subjects and study design

Between May 2009 and January 2013, NW and obese women were recruited early in pregnancy for the Pregnancy Obesity Nutrition and Child Health study (PONCH). ${ }^{14,15}$ This longitudinal randomized dietary intervention study focuses on several aspects of health during pregnancy, some of which are described. ${ }^{14,15}$ Inclusion criteria were age 20-45 years and BMI $18.5-24.9 \mathrm{~kg} \mathrm{~m}^{-2}$ or $>30 \mathrm{~kg} \mathrm{~m}^{-2}$. Exclusion criteria were non-European descent, diabetes, use of neuroleptic drugs, and vegetarianism or veganism.

Participants matched by age, BMI and parity were randomized to an intervention group, which received dietary counseling, or to a control group, which received only routine diet advice at the maternity care centers. The aim of the counseling, by dieticians, was to increase adherence to the Nordic Nutrition Recommendations. ${ }^{16} \mathrm{NW}$ and obese women, randomized to intervention, received the same dietary advice apart from energy intake recommendations. NW women were recommended to increase energy intake by $350 \mathrm{kcal} \mathrm{day}^{-1}$ in T2 and $500 \mathrm{kcal} \mathrm{day}^{-1}$ in T3. Obese women were recommended to reduce energy intake by $20 \%$, based on estimated energy needs. Participants who consented to an optional subcutaneous abdominal adipose tissue biopsy at study visits in T1 and T3 were included in this study $(n=33)$.

All participants received information about the study and gave oral and written consent. The study was performed at Sahlgrenska University Hospital, Gothenburg, Sweden, and was approved by the Regional Ethical Review Board, University of Gothenburg.

\section{Study procedure}

Study visits were scheduled in T1 (gestational weeks 8-12) and T3 (gestational weeks 35-37). The same examination protocol was used at both visits. Participants were instructed to fast overnight before study visits. Two NW women were not fasting at the time of examination in T1 and $\mathrm{T} 3$, respectively, allowing only for determination of body composition and adipose tissue morphology.

\section{Anthropometry and body composition}

Waist and hip circumferences and height were measured by standard protocols to the nearest $0.5 \mathrm{~cm}$. Body weight and volume, based on airdisplacement plethysmography (ADP), were assessed using Bod Pod (software version 4.2.1 and 5.2.0; Cosmed, Rome, Italy) as described. ${ }^{14,15}$ Body density was calculated and converted to body composition based on the two-component model. ${ }^{17}$ Body volume was corrected for thoracic gas volume predicted by the Bod Pod software. ${ }^{18} \mathrm{~A}$ fat-free mass density of $1.0895 \mathrm{~g} \mathrm{ml}^{-1}$ (an approximation in terms of the average fat-free mass density in weeks 30 and 40 ) was used in T3 because of increased hydration of fat-free mass late in pregnancy. ${ }^{19}$

Body composition was also assessed using bioelectrical impedance analysis (BIA; MC-180MA III multi-frequency eight-electrode, Tanita Corporation, Tokyo, Japan). For logistic reasons, one obese woman in T1 and two NW women in T3 were not examined using ADP. Linear regression revealed that fat mass $S_{\mathrm{BIA}}$ correlated with fat mass $\mathrm{ADP}_{\mathrm{A} P}$ (T1: $R=0.946$, $P<0.001, n=37$; T3: $R=0.932, P<0.001, n=13)$; fat mass ${ }_{\text {ADP }}$ could therefore be predicted for two of these women. For logistic reasons, circumferences were not measured in any trimester in one obese woman; hip circumference was not measured in one NW (T1) and one obese (T3) woman.

\section{Insulin resistance}

The homeostasis model assessment of insulin resistance (HOMA-IR), which correlates well with insulin resistance measured by the hyperinsulinemic euglycemic clamp technique during pregnancy $\left(R^{2}=0.53, P<0.0001\right),{ }^{20}$ was calculated as fasting insulin $\left(\mathrm{mUl}^{-1}\right) \times$ fasting glucose $\left(\mathrm{mmol} \mathrm{I}^{-1}\right) / 22.5{ }^{21}$

\section{Adipose tissue biopsy}

Under local anesthesia, subcutaneous adipose tissue was obtained by needle aspiration from the lateral abdomen, at the level of the umbilicus. The biopsy was prepared as described below.

\section{Adipokine release in vitro}

Explants of adipose tissue were incubated under sterile conditions to study adipokine release as described. ${ }^{22}$ In brief, about $250 \mathrm{mg}$ of adipose tissue was incubated in $10 \mathrm{ml}$ of medium. ${ }^{22}$ After $4 \mathrm{~h}$, the medium was separated from the tissue, centrifuged for $5 \mathrm{~min}$ at $450 \mathrm{~g}$, and stored at $-80^{\circ} \mathrm{C}$. Fresh medium $(10 \mathrm{ml})$ was added to the tissue; $20 \mathrm{~h}$ later, the medium was removed, centrifuged and stored as above. Adipokine concentrations were expressed per $\mathrm{g}$ adipose tissue. Adipokine release over $24 \mathrm{~h}$ was calculated as the sum of the concentrations in the two samples. For logistic reasons, adipokine release in vitro was not determined in three NW (T1) women and one obese $(\mathrm{T} 1 / \mathrm{T} 3)$ woman.

\section{Adipocyte size and number}

Each adipose tissue sample was digested with collagenase (Type A; Roche, Mannheim, Germany), an adipocyte suspension was prepared, and adipocyte size was determined by computerized image analysis s.23 $^{22,23}$ (Leica QWin V3; Leica Microsystems, Wetzlar, Germany). Twelve random visual fields were photographed (DFC320, Leica Microsystems). Microspheres $98 \mu \mathrm{m}$ in diameter (Dynal, Invitrogen, Oslo, Norway) served as reference. Adipocytes were classified very small ( $<50 \mu \mathrm{m}$ diameter), small $(50-100 \mu \mathrm{m})$, large $(100-150 \mu \mathrm{m})$ and very large $(>150 \mu \mathrm{m})$. The formulas for the cross-sectional area $\left(\pi d^{2} / 4\right)$ and the volume $\left(\pi d^{3} / 6\right)$ of a sphere were used in calculations of individual adipocyte size and weight (density $0.9 \mathrm{~g} \mathrm{ml}^{-1}$ ). In calculations of immune cell density (per $10^{3}$ adipocytes) and adipocyte glycerol release (per $10^{4}$ adipocytes), the sample adipocyte size/weight distribution was used. Mean adipocyte volume was determined as the average of all adipocyte volumes. Body adipocyte number was estimated by using body fat volume and the adipocyte volume distribution.

\section{Lipolysis}

Isolated adipocytes were incubated for $2 \mathrm{~h}$, without a lipolytic agent, and glycerol released into the medium was determined as an index of basal lipolysis as described. ${ }^{24}$ The amount of triglycerides in the adipocyte suspension was measured after extraction and evaporation of solvents. ${ }^{25}$ Incubations were performed in duplicate. Lipolytic activity was expressed as $\mathrm{nmol}$ glycerol per $\mathrm{g}$ triglyceride and per $10^{4}$ adipocytes. For logistic reasons, lipolytic activity was not determined in one obese woman (T1/T3).

\section{Immunohistochemistry}

Part of each biopsy was fixed in phosphate-buffered formalin, processed (Leica TP 1020, Leica Microsystems), embedded in paraffin and cut into 5$\mu \mathrm{m}$-thick sections. The sections were subjected to high-temperature antigen retrieval for 10 min in EDTA buffer, $\mathrm{pH}$ 8, followed by blocking and incubation with antibodies against macrophages (monoclonal mouse antihuman CD68 clone PG-M1, Dako, Glostrup, Denmark), mast cells (monoclonal mouse anti-human mast cell tryptase, clone AA1, Dako), and von Willebrand factor (polyclonal rabbit anti-human von Willebrand factor, Dako) to detect vessels. For visualization of immunoreactions, MACH3 mouse AP-polymer was used for macrophages and mast cells and MACH3 rabbit AP-polymer for vessels (Biocare Medical, Concord, CA, USA). The chromogen was Warp Red (Biocare Medical). Slides were counterstained with hematoxylin, mounted, scanned with Mirax Digital Desk Scanner (Zeiss, Göttingen, Germany), and analyzed with Tissue Studio 3.6.1 (Definiens, Munich, Germany). Macrophage and mast cell densities were expressed as the number of immunoreactive cells per $\mathrm{mm}^{2}$ and per $10^{3}$ adipocytes. Vessel density was expressed as the ratio of the positive signal area to the total specimen area.

\section{Biochemical assays}

All blood and medium samples were analyzed at the Clinical Chemistry Laboratory, Sahlgrenska University Hospital, accredited in accordance with the International Standard ISO 15189:2007. Enzyme-linked immunosorbent assay (ELISA) was used to measure adiponectin (Human adiponectin ELISA kit, Millipore, Billerica, MA, USA), tumor necrosis factor (TNF)- $a$ (human TNFalpha Quantikine HS ELISA, R\&D Systems, Minneapolis, MN, USA) and adipocyte fatty acid-binding protein (AFABP) (Human Adipocyte FABP ELISA kit, BioVendor Research and Diagnostic Products, Bratislava, Slovakia). As a result of a change in assay during the study period, leptin was measured by RIA or ELISA (Human Leptin RIA kit, Millipore; Quantikine Human Leptin, R\&D Systems; $R=0.962)$. Samples from each woman in T1 and T3 were analyzed with the same leptin assay. $\mathrm{HbA1c}$ was measured by Mono-S ion-exchange chromatography. Glycerol was analyzed with a Randox radiometric glycerol kit (GY105; Crumlin, UK) and a Konelab 30 autoanalyzer (Thermo Clinical Labsystems, Vantaa, Finland). All other 
assays were routinely performed with a Cobas Modular system (Roche Diagnostics, Mannheim, Germany).

\section{Statistical analysis}

Values are given as mean \pm s.d. or mean (range). The related samples Wilcoxon signed-rank test was used to assess differences between early and late in pregnancy within groups. The independent samples Mann-Whitney U-test was used to compare NW and obese subjects, and changes between groups. Multivariable linear regression was used to identify determinants of HOMA-IR early and late in gestation. Variables correlated with HOMA-IR by Spearman's rank correlation test were selected as independent variables in separate regression analyses of data from $\mathrm{T} 1$ and T3. Spearman's rank correlation test was also used to evaluate associations between adipocyte size in $\mathrm{T} 1$ and the change in the proportion of adipocytes $<100 \mu \mathrm{m}$ during pregnancy, and between the proportion of adipocytes $>150 \mu \mathrm{m}$ and circulating adipokines in T3. Linear regression was used to evaluate the relationship of values from ADP and bioelectrical impedance analysis and the two leptin assays, respectively. $P<0.05$ was considered significant. All statistical analyses were performed in SPSS (v. 21 for MacOS X, SPSS, Chicago, IL, USA).

\section{RESULTS}

Thirty-three pregnant women, 22 NW and 11 obese, were allocated to a control group (9 NW, 6 obese) or a dietary counseling group (13 NW, 5 obese). The women in control and intervention groups did not differ in energy intake, macronutrient percentage of energy intake, body composition or metabolic status in $\mathrm{T} 1$ or during pregnancy (except in the percentage of calories from protein in NW women). Therefore, NW and obese women in the control and dietary counseling groups were separately pooled (Supplementary Tables 1 and 2).

There were no differences between NW and obese groups in parity $(0.6 \pm 0.6$ vs $0.9 \pm 0.8$, nonsignificant (NS)) or gestational day at the study visits in T1 ( $82 \pm 7$ vs $80 \pm 11, N S)$ or T3 ( $252 \pm 9$ vs $247 \pm 8, N S$ ).
T1 whole-body characteristics

Characteristics of NW and obese women in T1 are shown in Table 1. The mean BMI was 22.3 (range 19.1-23.9) and 35.3 (30.4-41.8) $\mathrm{kg} \mathrm{m}^{-2}$, respectively. One of the obese women had a BMI above $40\left(41.8 \mathrm{~kg} \mathrm{~m}^{-2}\right)$. BMI range among the remaining 10 women was $30.4-39.5 \mathrm{~kg} \mathrm{~m}^{-2}$. There was no difference in age between the groups. As expected, fat mass, leptin, AFABP and HOMA-IR were higher in the obese women, and circulating adiponectin was lower.

\section{Changes in whole-body characteristics during pregnancy}

Fat mass and HOMA-IR increased similarly between trimesters when the groups of NW and obese women were compared, although fat mass was not influenced $(P=0.050)$ within the group of obese women (Table 1). Fat mass was reduced in one NW $(-2.5 \mathrm{~kg})$ and three obese women $(-1.7,-4.0$ and $-2.1 \mathrm{~kg})$. Leptin and AFABP also increased similarly in comparison of the groups, although leptin was not influenced in obese women. Adiponectin was reduced within the group of NW, but not in obese, women. Comparison of the groups revealed a greater reduction in adiponectin in the NW group. Late in pregnancy, adiponectin concentrations were similar in the two groups (Table 1). Exclusion of the four women with reduced fat mass during pregnancy revealed an increase in fat mass within the group of NW $(4.7 \mathrm{~kg})$ and obese women $(5.0 \mathrm{~kg})$ and the fat mass gain did not differ between the groups.

\section{Adipose tissue characteristics in T1}

Adipose tissue characteristics in $\mathrm{T} 1$ are shown in Table 2. Obese women had more and larger adipocytes than NW women early in pregnancy. In relative terms, obese women also had fewer small fat cells and more large and very large cells. The mean diameter of reference microspheres was $97.75 \pm 0.15 \mu \mathrm{m}(n=50)$. In each cell population, 414-2395 cells (mean 1295 \pm 460 ) were analyzed. Adipokine release in vitro and immune cell (per $10^{3}$ adipocytes not

Table 1. Whole-body characteristics of NW $(n=22)$ and obese $(n=11)$ pregnant women in T1 and T3

\begin{tabular}{|c|c|c|c|c|c|c|c|c|c|}
\hline \multirow[t]{2}{*}{ Characteristic } & \multicolumn{2}{|c|}{$N W$} & \multirow[t]{2}{*}{ P-value } & \multicolumn{2}{|c|}{ Obese } & \multirow[t]{2}{*}{ P-value ${ }^{\mathrm{a}}$} & \multirow{2}{*}{\multicolumn{2}{|c|}{$\begin{array}{c}\text { NW Obese } \\
\text { Change from } T 1 \text { to } T 3\end{array}$}} & \multirow[t]{2}{*}{ P-value } \\
\hline & $T 1$ & T3 & & $T 1$ & T3 & & & & \\
\hline Age (years) & $31.3 \pm 4.0$ & & & $30.9 \pm 3.0$ & & & & & \\
\hline Weight (kg) & $61.8 \pm 6.7$ & $73.9 \pm 7.3$ & $<0.001$ & $102.5 \pm 9.9^{c}$ & $112.6 \pm 10.8^{c}$ & $<0.01$ & $12.1 \pm 2.8$ & $10.0 \pm 5.6$ & NS \\
\hline BMI $\left(\mathrm{kg} \mathrm{m}^{-2}\right)$ & $22.3 \pm 1.3$ & & & $35.3 \pm 3.5^{c}$ & & & & & \\
\hline Waist circumference $(\mathrm{cm})$ & $79.7 \pm 7.8$ & & & $110.3 \pm 8.1^{c}$ & & & & & \\
\hline Hip circumference (cm) & $95.3 \pm 9.4$ & $101.0 \pm 8.9$ & $<0.001$ & $125.6 \pm 7.7^{c}$ & $127.1 \pm 9.4^{c}$ & NS & $5.6 \pm 3.0$ & $1.4 \pm 6.1$ & $<0.05$ \\
\hline Fat mass (kg) & $16.3 \pm 4.6$ & $20.6 \pm 5.4$ & $<0.001$ & $47.3 \pm 8.9^{c}$ & $50.3 \pm 9.1^{c}$ & $P=0.050$ & $4.4 \pm 2.8$ & $3.0 \pm 4.2$ & NS \\
\hline Fat mass (\%) & $26.1 \pm 6.5$ & $27.7 \pm 6.1$ & $<0.05$ & $45.8 \pm 5.0^{c}$ & $44.4 \pm 4.6^{c}$ & NS & $1.5 \pm 3.3$ & $-1.5 \pm 2.4$ & $<0.01$ \\
\hline Fat-free mass (kg) & $45.5 \pm 5.5$ & $53.3 \pm 5.9$ & $<0.001$ & $55.2 \pm 3.8^{c}$ & $62.3 \pm 4.5^{c}$ & $<0.01$ & $7.8 \pm 2.1$ & $7.1 \pm 3.1$ & NS \\
\hline Fat-free mass (\%) & $73.9 \pm 6.5$ & $72.3 \pm 6.1$ & $<0.05$ & $54.2 \pm 5.0^{c}$ & $55.6 \pm 4.6^{c}$ & NS & $-1.5 \pm 3.3$ & $1.5 \pm 2.4$ & $<0.01$ \\
\hline S-cholesterol $\left(\mathrm{mmoll}^{-1}\right)$ & $4.5 \pm 0.7$ & $7.2 \pm 1.0$ & $<0.001$ & $4.9 \pm 0.6$ & $6.5 \pm 0.8^{a}$ & $<0.01$ & $2.7 \pm 0.9$ & $1.6 \pm 0.6$ & $<0.05$ \\
\hline S-HDL (mmol I-1) & $2.1 \pm 0.3$ & $2.0 \pm 0.4$ & NS & $1.8 \pm 0.3$ & $1.8 \pm 0.4$ & NS & $-0.1 \pm 0.3$ & $0.0 \pm 0.3$ & NS \\
\hline S-LDL $\left(\mathrm{mmoll}^{-1}\right)$ & $2.4 \pm 0.6$ & $4.7 \pm 1.0$ & $<0.001$ & $2.7 \pm 0.6$ & $3.9 \pm 0.7$ & $<0.01$ & $2.3 \pm 0.9$ & $1.2 \pm 0.6$ & $<0.001$ \\
\hline P-glucose $\left(\mathrm{mmoll}^{-1}\right)$ & $4.4 \pm 0.2$ & $4.2 \pm 0.3$ & $<0.05$ & $4.7 \pm 0.3^{b}$ & $4.7 \pm 0.3^{b}$ & NS & $-0.2 \pm 0.3$ & $0.0 \pm 0.4$ & NS \\
\hline S-insulin $\left(\mathrm{mU} \mathrm{I}^{-1}\right)$ & $4.3 \pm 0.9$ & $7.7 \pm 3.3$ & $<0.001$ & $11.9 \pm 4.2^{C}$ & $18.7 \pm 6.1^{c}$ & $<0.01$ & $3.4 \pm 2.9$ & $6.9 \pm 6.0$ & $<0.05$ \\
\hline $\mathrm{HbA} 1 \mathrm{c}\left(\mathrm{mmol} \mathrm{mol}{ }^{-1}\right)$ & $29.3 \pm 2.5$ & $30.2 \pm 2.8$ & NS & $30.7 \pm 2.1$ & $31.5 \pm 2.9$ & NS & $0.8 \pm 2.2$ & $0.8 \pm 2.9$ & NS \\
\hline HOMA-IR & $0.83 \pm 0.19$ & $1.47 \pm 0.71$ & $<0.001$ & $2.47 \pm 0.85^{c}$ & $3.91 \pm 1.35^{c}$ & $<0.05$ & $0.64 \pm 0.61$ & $1.44 \pm 1.43$ & NS \\
\hline S-hsCRP $\left(\mathrm{mg} \mathrm{l}^{-1}\right)^{\mathrm{c}}$ & $2.9 \pm 1.9$ & $3.8 \pm 2.3$ & $<0.05$ & $4.7 \pm 2.1^{\mathrm{a}}$ & $3.6 \pm 2.3$ & NS & $0.9 \pm 2.1$ & $-1.2 \pm 2.5$ & $<0.05$ \\
\hline S-leptin $\left(\mu \mathrm{g} \mathrm{I^{-1 }}\right)$ & $12.5 \pm 5.7$ & $16.4 \pm 7.1$ & $<0.05$ & $48.5 \pm 15.1^{c}$ & $52.2 \pm 22.4^{c}$ & NS & $3.9 \pm 5.7$ & $3.7 \pm 18.1$ & NS \\
\hline S-adiponectin $\left(\mathrm{mgl}^{-1}\right)$ & $16.9 \pm 7.5$ & $11.8 \pm 5.2$ & $<0.01$ & $10.4 \pm 4.5^{\mathrm{b}}$ & $9.1 \pm 3.5$ & NS & $-5.1 \pm 5.2$ & $-1.3 \pm 2.6$ & $<0.05$ \\
\hline S-AFABP $\left(\mu \mathrm{gl}^{-1}\right)$ & $9.0 \pm 3.1$ & $13.5 \pm 4.6$ & $<0.001$ & $21.4 \pm 10.7^{c}$ & $33.4 \pm 17.2^{c}$ & $<0.01$ & $4.6 \pm 3.0$ & $12.0 \pm 12.3$ & NS \\
\hline
\end{tabular}

Abbreviations: BMI, body mass index; HbA1c, glycated hemoglobin; HDL, high-density lipoprotein; HOMA-IR, homeostasis model assessment of insulin resistance; hsCRP, high-sensitivity C-reactive protein; LDL, low-density lipoprotein; NS, nonsignificant; NW, normal weight; P, plasma; S, serum. ${ }^{2}$ Related samples Wilcoxon signed-rank test. ${ }^{b}$ Independent samples Mann-Whitney $U$-test: ${ }^{\mathrm{a}} P<0.05,{ }^{\mathrm{b}} P<0.01,{ }^{\mathrm{c}} P<0.001$ vs NW in corresponding trimester. ${ }^{\mathrm{C}} \mathrm{One} \mathrm{NW}$ and three obese women with hsCRP concentrations $>10 \mathrm{mgl}^{-1}$ were excluded. Values are mean \pm s.d. 


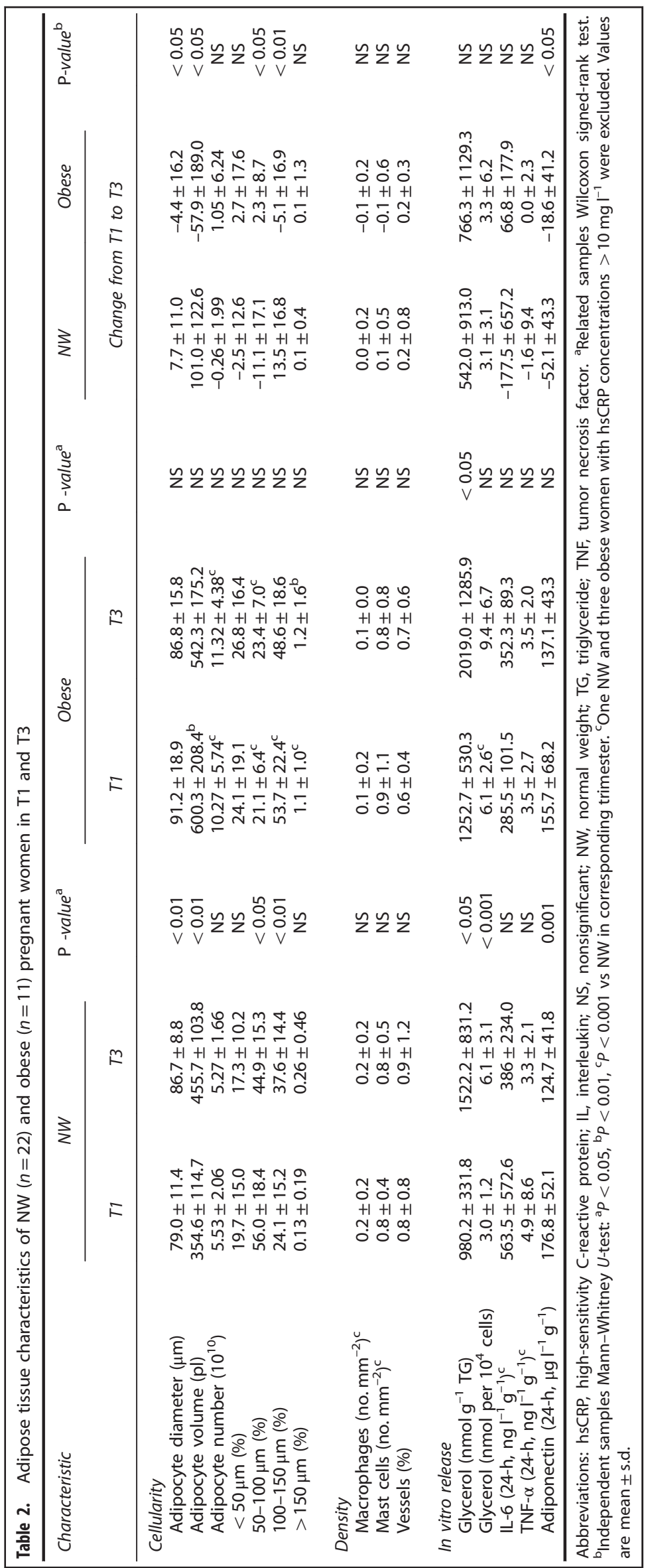


shown) and vessel densities did not differ between the groups. Obese women had higher lipolytic activity as expressed per cell. Representative images of isolated cells and tissue sections are shown in Figure 1.

Changes in adipose tissue characteristics during pregnancy Between T1 and T3, adipocyte diameter and volume increased in NW women but not in obese women (Table 2). Comparison of the groups revealed that adipocyte size changed in opposite directions in NW and obese women. The total number of adipocytes was not influenced during pregnancy. However, in NW women, the proportion of small cells decreased and the proportion of large cells increased; the opposite was observed in obese women. Adipocyte diameter in T1 correlated with the change in the proportion of adipocytes $<100 \mu \mathrm{m}$ during pregnancy $(\rho=0.616, P<0.001, n=33)$ (Figure 2$)$. Exclusion of the four women with reduced fat mass during pregnancy confirmed the observed pattern but revealed also an increased adipocyte number in the obese group when the groups were compared. Adipocyte diameter in T1 correlated with the change in the proportion of adipocytes $<100 \mu \mathrm{m}$ during pregnancy $(\rho=0.597, P<0.001, n=28)$.

Lipolytic activity increased during pregnancy in both groups. As observed in vivo (Table 1), adiponectin release in vitro decreased during pregnancy in NW but not in obese women. Comparison of the groups revealed a more marked reduction in adiponectin release in the NW group. Late in pregnancy, adiponectin release was similar in the two groups (Table 2). There were no changes in the in vitro release of interleukin- 6 and TNF- $a$ and in the densities of immune cells (per $10^{3}$ adipocytes not shown) and blood vessels during pregnancy in the groups. Exclusion of the four women with reduced fat mass during pregnancy confirmed the findings with two exceptions. The lipolytic activity within the obese group was not significantly influenced. Instead, comparison of the groups revealed a greater increase in lipolytic activity, expressed per cell, in the NW group.
Factors associated with insulin resistance early and late in pregnancy

Multivariable linear regression analysis was performed with HOMA-IR in T1 and T3, respectively, as depending variable. All whole-body and adipose tissue characteristics that correlated significantly with HOMA-IR in the corresponding trimester were introduced as independent variables (Table 3). In the final analyses of $\mathrm{T} 1$ and T3, a complete data set was available for 31 women (data on lipolysis and HOMA-IR were missing in one woman each in $\mathrm{T} 1$; fat mass and HOMA-IR were missing in one woman each in T3).

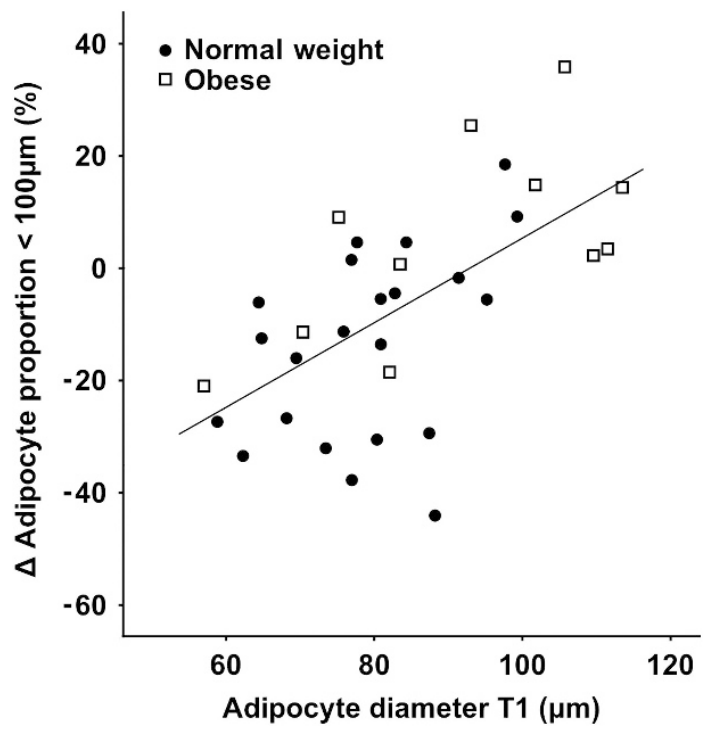

Figure 2. Correlation between adipocyte diameter in T1 and change in the proportion of adipocytes $<100 \mu \mathrm{m}$ in diameter during pregnancy in NW and obese women $(\rho=0.616, P<0.001, n=33)$.

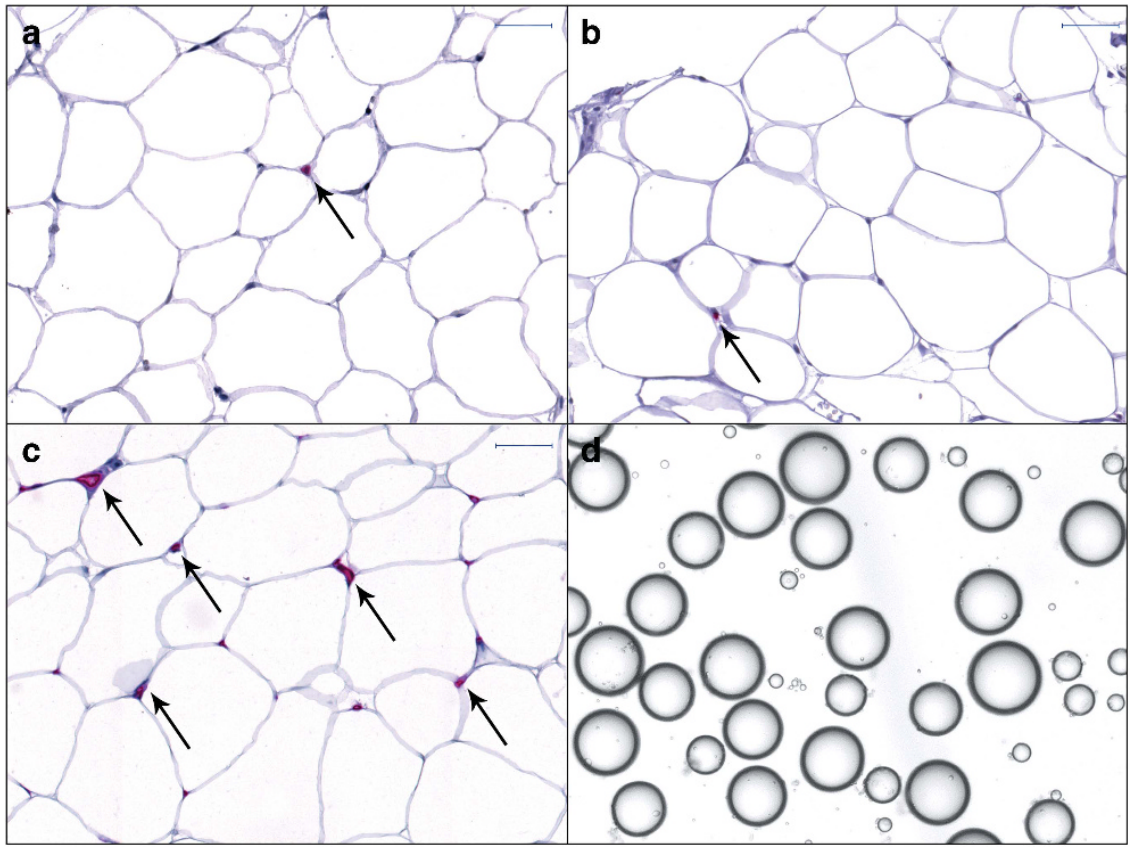

Figure 1. Adipose tissue sections (a-c) and isolated adipocytes (d) from a NW pregnant woman in T1. The sections were stained with antibodies against mast cell tryptase to detect mast cells (a), CD68 to detect macrophages (b) and von Willebrand factor to visualize vessels (c). Warp Red was used as the chromogen. Slides were counterstained with hematoxylin. Arrows indicate positive immunoreactions. Scale bar represents $50 \mu \mathrm{m}$. 
Table 3. Factors associated with insulin resistance in $\mathrm{T} 1$ and $\mathrm{T} 3$

\begin{tabular}{cllc}
\hline & Variables & $\beta$ & $\mathrm{R}^{2}$ \\
\hline T1 model & & & \\
I & Weight $(\mathrm{kg})$ & $0.902^{* * *}$ & $0.807^{* * * *}$ \\
II & Weight $(\mathrm{kg})$ & $0.666^{* * *}$ & $0.866^{* * * *}$ \\
& Glycerol $\left(\mathrm{nmol}\right.$ per $10^{4}$ cells) & $0.343^{* *}$ & \\
III & Weight $(\mathrm{kg})$ & $0.356^{*}$ & $0.885^{* * *}$ \\
& Glycerol $\left(\mathrm{nmol}\right.$ per $10^{4}$ cells) & $0.371^{* * *}$ & \\
& Leptin $\left.(\mu \mathrm{g} \mathrm{I})^{-1}\right)$ & $0.325^{*}$ & \\
& & & \\
T3 model & & $0.848^{* * *}$ & $0.708^{* * *}$ \\
I & Body fat mass $(\mathrm{kg})$ & $0.714^{* * *}$ & $0.751^{* * *}$ \\
II & Body fat mass $(\mathrm{kg})$ & $0.261^{*}$ & \\
& Adipocytes $>150 \mu \mathrm{m}(\%)$ & \\
\hline
\end{tabular}

Abbreviations: AFABP, adipocyte fatty acid-binding protein; BMl, body mass index; HbA1c, glycated hemoglobin; HOMA-IR, homeostasis model assessment of insulin resistance; $S$, serum. ${ }^{*} P<0.05,{ }^{*} P<0.01 * * * P<0.001, n=31$ Multivariable linear regression (stepwise) with HOMA-IR in T1 and T3, respectively, as the dependent variable. T3 independent variables: weight, body fat mass (absolute value and in relation to body weight), fat-free mass (in relation to body weight), hip circumference, S-cholesterol, S-leptin, S-AFABP, adipocyte volume, total number of adipocytes, number of adipocytes $50-100 \mu \mathrm{m}$ (in relation to total number), number of adipocytes $100-150 \mu \mathrm{m}$ (absolute value and in relation to total number) and number of adipocytes $>150 \mu \mathrm{m}$ (absolute value and in relation to total number). T1 independent variables: the same as for T3 plus $\mathrm{HbA1c}$, S-adiponectin, 20-h adiponectin release in vitro, BMl, waist circumference, fat-free mass (absolute value), glycerol (nmol per $10^{4}$ adipocytes), number of adipocytes $<50 \mu \mathrm{m}$ (absolute value) and number of adipocytes $50-100 \mu \mathrm{m}$ (absolute value). Inclusion criterion of the model was an $\mathrm{F}$ probability of 0.05 and exclusion criterion was an $\mathrm{F}$ probability of $0.1 . \beta, \beta$ standardized coefficient; $R^{2}$, adjusted determination coefficient.

Early in pregnancy, the best regression model included weight, basal lipolytic activity, and serum leptin and explained $88.5 \%$ of the variance in HOMA-IR $(P<0.001)$. The variable most strongly associated (highest correlation coefficient) with insulin resistance was weight.

Late in pregnancy, the best regression model included fat mass and the proportion of very large adipocytes and explained $75.1 \%$ of the variance in HOMA-IR $(P<0.001)$. The variable most strongly associated with insulin resistance was fat mass. The proportion of very large adipocytes also correlated with circulating levels of $\operatorname{AFABP}(\rho=0.45, P<0.01, n=32)$, an adipokine that also correlated with HOMA-IR.

\section{DISCUSSION}

This longitudinal study shows that adipose tissue morphology and function undergo comprehensive changes during pregnancy, and many of the changes differed in NW and obese women. Although weight gain and fat mass gain, in absolute terms, did not differ between the two groups, mean adipocyte size and the proportion of fat cells in the size classes were oppositely influenced: NW women had increased mean adipocyte size and a higher proportion of large cells. Further, lipolytic activity and circulating leptin and AFABP increased similarly in both NW and obese women, whereas the release of adiponectin, in vivo and in vitro, decreased more markedly in the NW group. Finally, body fat mass and the proportion of very large adipocytes were strongly associated with gestational insulin resistance. Exclusion of the four women with reduced fat mass during pregnancy confirmed the observations of opposite changes of adipocyte size and proportions in the groups and revealed also an increased adipocyte number in the obese group when the groups were compared.
In previous studies of body composition changes during pregnancy and the influence of obesity, ${ }^{26-28}$ fat mass increased on average $0.2-4.0 \mathrm{~kg}$ under conditions similar to ours, consistent with the present findings. In these studies, obese women accumulated less fat, ${ }^{26}$ a similar amount of fat, ${ }^{27}$ or more fat ${ }^{28}$ than NW women. These discrepancies may reflect differences in total weight gain between the groups, as fat gain correlates positively with weight gain. ${ }^{26,28}$ Methodological aspects may also be important. Previous studies applied four-component models ${ }^{26,28}$ and a two-component model based on underwater weighing. ${ }^{27}$ The method we used, ADP, is an accurate, rapid and safe technique for assessing body composition in a wide range of subject types. ${ }^{29}$ The two-component model, based on appropriate fat-free mass density values, provides useful body composition results also during pregnancy. ${ }^{30}$

During non-pregnancy, accumulation of fat in subcutaneous adipose tissue is regulated by expansion of existing adipocytes (hypertrophy) or by generation of new adipocytes (hyperplasia). Adipocyte hypertrophy may result in inflamed and dysfunctional adipose tissue and promote ectopic fat accumulation and insulin resistance, whereas adipocyte hyperplasia is protective. ${ }^{31,32}$ In our NW pregnant women, mean adipocyte size increased during pregnancy, but adipocyte number was unchanged. Moreover, in NW women, the proportion of large fat cells increased at the expense of small cells, indicating that fat mainly accumulated in existing adipocytes. Adiponectin release, which correlates negatively with adipocyte size, ${ }^{22,33}$ was also reduced in the NW group. In obese women, the number of adipocytes was not affected during pregnancy. However, when women with reduced fat mass during pregnancy were omitted from the analysis, to avoid findings of reduced adipocyte size because of reduced fat mass, adipocyte number was increased in the obese group when the groups were compared. Further, in comparison with the NW group, mean adipocyte size decreased in obese women and the proportion of large cells decreased-the opposite of what was seen in NW women. These findings suggest adipocyte recruitment in obese women during pregnancy. In obese women, adiponectin was not as reduced as in NW women, further supporting this scenario. Although conclusions regarding the obese group must be drawn with caution, because of lack of significant changes within the group, we speculate that the indicated changes in adipose tissue cellularity during pregnancy in obese women help protect against even more severe insulin resistance. This reasoning is in line also with the positive correlation between adipocyte size in T1 and the change in the proportion of cells $<100 \mu \mathrm{m}$ during pregnancy. In addition, adipocyte recruitment has been reported in both pregnant women ${ }^{12}$ and nonpregnant women. ${ }^{34}$

Chronic low-grade inflammation is closely linked to obesity and insulin resistance ${ }^{35}$ and, although insufficiently investigated, it has been suggested that increased inflammatory activity is involved in mediating adverse clinical outcomes during pregnancy. ${ }^{36}$ Obese women in this study had higher concentrations of C-reactive protein (CRP) than NW women in T1, but CRP increased during pregnancy in the NW group, and in T3 there was no difference between groups. This is in agreement with the finding that BMI-dependent increases in common proinflammatory markers such as CRP and interleukin- 6 are not evident at the end of pregnancy. ${ }^{37}$ Interestingly, circulating levels of AFABP, a marker of metabolic disease and also implicated in inflammation, ${ }^{38}$ increased in both groups during pregnancy and were consistently higher in the obese women. However, neither adipose tissue release of interleukin-6 and TNF-a in vitro nor the density of immune cells and vessels was influenced during pregnancy or by obesity. By contrast, in other studies, pre-gravid obesity was associated with increased maternal endotoxemia and metabolic inflammation, including accumulation of macrophages in adipose tissue, at the time of elective cesarean delivery at term. ${ }^{39}$ One plausible factor that may explain the differences is that the 
women in these previous studies had higher BMI, circulating leptin and HOMA-IR and markedly higher CRP than the women in our study. ${ }^{39}$ We excluded women with CRP $>10 \mathrm{mgl}^{-1}$ in analyses of immune-related variables to exclude subjects with signs of clinical inflammation. ${ }^{40}$

In multivariable linear regression, analysis to identify adiposetissue-related factors associated with gestational insulin resistance, fat mass and the proportion of very large adipocytes together explained $75 \%$ of HOMA-IR in T3. Thus, as observed previously, fat mass late in pregnancy has a significant effect on the development of gestational insulin resistance. ${ }^{41}$ If adipose tissue late in pregnancy is characterized also by hypertrophy, rather than hyperplasia, insulin resistance may be even greater. The mechanism of the effect of very large fat cells on gestational insulin resistance is likely to be multifactorial. ${ }^{31}$ Interestingly, late in pregnancy the proportion of very large adipocytes correlated with circulating levels of AFABP. Multivariable analysis of data from T1 showed that weight, basal lipolytic activity, and serum leptin constituted the best model, pointing to the fact that insulin resistance is regulated via partly varying factors depending on gestational period.

This is the first comprehensive, longitudinal analysis of adipose tissue during pregnancy and its effect on gestational insulin resistance. The technique we used to measure adipocyte size enabled us to obtain a large number of observations and reliable size distributions. However, some limitations need to be considered. Fat gain starts early in pregnancy, and a prepregnancy biopsy would have been valuable to further evaluate the effect of pregnancy per se on adipose tissue biology. Our calculations of adipocyte number are based solely on the fat cell size distribution in the abdominal region. Although fat cell size does not differ much between body regions, ${ }^{42}$ an additional biopsy from another region (for example, gluteo-femoral) would have been valuable. Further, the relatively small number of women, particularly in the obese group, limited the statistical power of our analyses.

Nevertheless, our findings show that adipose tissue morphology and function change extensively during pregnancy. Mean adipocyte size and the proportion of small and large adipocytes were oppositely influenced during pregnancy in NW and obese women. Adipocyte size in T1 correlated positively with the change in the proportion of small adipocytes, indicating that fat cells may be recruited during pregnancy. Further, excess body fat and a high proportion of large adipocytes may significantly contribute to insulin resistance late in gestation. These findings add valuable information to our knowledge in this field and point to the importance of elucidating the mechanisms of normal and adverse clinical outcomes during pregnancy.

\section{CONFLICT OF INTEREST}

The authors declare no conflict of interest.

\section{ACKNOWLEDGEMENTS}

We thank the Department of Clinical Chemistry, Sahlgrenska University Hospital, and Carola Gustafsson, Department of Cardiology, Sahlgrenska University Hospital, for excellent technical assistance, members of the $\mathrm{PONCH}$ group, Institute of Neuroscience and Physiology, Sahlgrenska Academy, for managing the main study, and Stephen Ordway, Golden Gate Biomedical Communications, San Francisco, CA, USA, for editorial assistance. This study was funded by the Swedish Research Council (K2007-54X-20325-01-3, 12206), Swedish Diabetes Association Research Foundation (DIA2007-027, DIA2010-086), the Swedish government under the LUA/ALF agreement, Novo Nordisk Foundation, IngaBritt and Arne Lundberg Foundation, Freemasonry Barnhus Board in Gothenburg, Queen Silvia's Jubilee Fund, Swedish Nutrition Foundation, Adlerbertska Foundation, Elin and Carl Linder Foundation, Per and Sara Hedenlöf Foundation, Wilhelm and Martina Lundgren Foundation, and Lisa and Johan Grönberg Foundation.

\section{REFERENCES}

1 Nolan CJ, Damm P, Prentki M. Type 2 diabetes across generations: from pathophysiology to prevention and management. Lancet 2011; 378: 169-181.

2 Butte NF. Carbohydrate and lipid metabolism in pregnancy: normal compared with gestational diabetes mellitus. Am J Clin Nutr 2000; 71: 1256S-1261S.

3 Newbern D, Freemark M. Placental hormones and the control of maternal metabolism and fetal growth. Curr Opin Endocrinol Diabetes Obes 2011; 18: 409-416.

4 Lacroix M, Kina E, Hivert MF. Maternal/fetal determinants of insulin resistance in women during pregnancy and in offspring over life. Curr Diab Rep 2013; 13: 238-244.

5 Catalano PM, Roman-Drago NM, Amini SB, Sims EA. Longitudinal changes in body composition and energy balance in lean women with normal and abnormal glucose tolerance during pregnancy. Am J Obstet Gynecol 1998; 179: 156-165.

6 Mclntyre HD, Chang AM, Callaway LK, Cowley DM, Dyer AR, Radaelli T et al. Hormonal and metabolic factors associated with variations in insulin sensitivity in human pregnancy. Diabetes Care 2010; 33: 356-360.

7 Retnakaran R, Qi Y, Sermer M, Connelly PW, Zinman B, Hanley AJ. Pre-gravid physical activity and reduced risk of glucose intolerance in pregnancy: the role of insulin sensitivity. Clin Endocrinol (Oxf) 2009; 70: 615-622.

8 Torloni MR, Betran AP, Horta BL, Nakamura MU, Atallah AN, Moron AF et al. Prepregnancy BMI and the risk of gestational diabetes: a systematic review of the literature with meta-analysis. Obes Rev 2009; 10: 194-203.

9 Elliott JA. The effect of pregnancy on the control of lipolysis in fat cells isolated from human adipose tissue. Eur J Clin Invest 1975; 5: 159-163.

10 Eriksson B, Lof $M$, Olausson $H$, Forsum E. Body fat, insulin resistance, energy expenditure and serum concentrations of leptin, adiponectin and resistin before, during and after pregnancy in healthy Swedish women. Br J Nutr 2010; 103: 50-57.

11 Pipe NG, Smith T, Halliday D, Edmonds CJ, Williams C, Coltart TM. Changes in fat, fat-free mass and body water in human normal pregnancy. Br J Obstet Gynaecol 1979; 86: 929-940.

12 Resi V, Basu S, Haghiac M, Presley L, Minium J, Kaufman B et al. Molecular inflammation and adipose tissue matrix remodeling precede physiological adaptations to pregnancy. Am J Physiol Endocrinol Metab 2012; 303: E832-E840.

13 Sohlstrom A, Forsum E. Changes in adipose tissue volume and distribution during reproduction in Swedish women as assessed by magnetic resonance imaging. Am J Clin Nutr 1995; 61: 287-295.

14 Karlsson T, Andersson L, Hussain A, Bosaeus M, Jansson N, Osmancevic A et al. Lower vitamin $D$ status in obese compared with normal-weight women despite higher vitamin D intake in early pregnancy. Clin Nutr 2014; 34: 892-898.

15 Bosaeus M, Hussain A, Karlsson T, Andersson L, Hulthen L, Svelander C et al. A randomized longitudinal dietary intervention study during pregnancy: effects on fish intake, phospholipids, and body composition. Nutr J 2015; 14: 1.

16 Nordiska ministerrådet. Nordic Nutrition Recommendations 2004. Integrating Nutrition and Physical Activity4th edn.Nordic Council of Ministers: Copenhagen: Denmark, 2004.

17 Siri WE. Body composition from fluid spaces and density: analysis of methods. 1961. Nutrition 1993; 9: 480-491; discussion 480, 492.

18 Henriksson P, Lof M, Forsum E. Assessment and prediction of thoracic gas volume in pregnant women: an evaluation in relation to body composition assessment using air displacement plethysmography. Br J Nutr 2013; 109: 111-117.

19 van Raaij JM, Peek ME, Vermaat-Miedema SH, Schonk CM, Hautvast JG. New equations for estimating body fat mass in pregnancy from body density or total body water. Am J Clin Nutr 1988; 48: 24-29.

20 Catalano PM, Kirwan JP. Clinical utility and approaches for estimating insulin sensitivity in pregnancy. Semin Perinatol 2002; 26: 181-189.

21 Matthews DR, Hosker JP, Rudenski AS, Naylor BA, Treacher DF, Turner RC. Homeostasis model assessment: insulin resistance and beta-cell function from fasting plasma glucose and insulin concentrations in man. Diabetologia 1985; 28 : 412-419.

22 Svensson $\mathrm{H}$, Oden B, Eden S, Lonn M. Adiponectin, chemerin, cytokines, and dipeptidyl peptidase 4 are released from human adipose tissue in a depotdependent manner: an in vitro system including human serum albumin. BMC Endocr Disord 2014; 14: 7.

23 Bjornheden T, Jakubowicz B, Levin M, Oden B, Eden S, Sjostrom L et al. Computerized determination of adipocyte size. Obes Res 2004; 12: 95-105.

24 Ottosson M, Lonnroth P, Bjorntorp P, Eden S. Effects of cortisol and growth hormone on lipolysis in human adipose tissue. J Clin Endocrinol Metab 2000; 85: 799-803.

25 Dole VP, Meinertz H. Microdetermination of long-chain fatty acids in plasma and tissues. J Biol Chem 1960; 235: 2595-2599.

26 Lederman SA, Paxton A, Heymsfield SB, Wang J, Thornton J, Pierson RN Jr. Body fat and water changes during pregnancy in women with different body weight and weight gain. Obstet Gynecol 1997; 90: 483-488. 
27 Ehrenberg HM, Huston-Presley L, Catalano PM. The influence of obesity and gestational diabetes mellitus on accretion and the distribution of adipose tissue in pregnancy. Am J Obstet Gynecol 2003; 189: 944-948.

28 Butte NF, Ellis KJ, Wong WW, Hopkinson JM, Smith EO. Composition of gestational weight gain impacts maternal fat retention and infant birth weight. Am J Obstet Gynecol 2003; 189: 1423-1432.

29 Fields DA, Goran Ml, McCrory MA. Body-composition assessment via air-displacement plethysmography in adults and children: a review. Am J Clin Nutr 2002; 75: 453-467.

30 Forsum E, Henriksson P, Lof M. The two-component model for calculating total body fat from body density: an evaluation in healthy women before, during and after pregnancy. Nutrients 2014; 6: 5888-5899.

31 Gustafson B, Hedjazifar S, Gogg S, Hammarstedt A, Smith U. Insulin resistance and impaired adipogenesis. Trends Endocrinol Metab 2015; 26: 193-200.

32 Jernas M, Palming J, Sjoholm K, Jennische E, Svensson PA, Gabrielsson BG et al. Separation of human adipocytes by size: hypertrophic fat cells display distinct gene expression. FASEB J 2006; 20: 1540-1542.

33 Hammarstedt A, Graham TE, Kahn BB. Adipose tissue dysregulation and reduced insulin sensitivity in non-obese individuals with enlarged abdominal adipose cells. Diabetol Metab Syndr 2012; 4: 42.

34 Tchoukalova YD, Votruba SB, Tchkonia T, Giorgadze N, Kirkland JL, Jensen MD. Regional differences in cellular mechanisms of adipose tissue gain with overfeeding. Proc Natl Acad Sci USA 2010; 107: 18226-18231.

35 Hotamisligil GS. Inflammation and metabolic disorders. Nature 2006; 444: 860-867.
36 Denison FC, Roberts KA, Barr SM, Norman JE. Obesity, pregnancy, inflammation, and vascular function. Reproduction 2010; 140: 373-385.

37 Friis CM, Paasche Roland MC, Godang K, Ueland T, Tanbo T, Bollerslev J et al. Adiposityrelated inflammation: effects of pregnancy. Obesity (Silver Spring) 2013; 21: E124-E130.

38 Kralisch S, Fasshauer M. Adipocyte fatty acid binding protein: a novel adipokine involved in the pathogenesis of metabolic and vascular disease? Diabetologia 2013; 56: 10-21.

39 Basu S, Haghiac M, Surace P, Challier JC, Guerre-Millo M, Singh K et al. Pregravid obesity associates with increased maternal endotoxemia and metabolic inflammation. Obesity (Silver Spring) 2011; 19: 476-482.

40 Ridker PM. Clinical application of C-reactive protein for cardiovascular disease detection and prevention. Circulation 2003; 107: 363-369.

41 Ahlsson F, Diderholm B, Jonsson B, Norden-Lindberg S, Olsson R, Ewald U et al. Insulin resistance, a link between maternal overweight and fetal macrosomia in nondiabetic pregnancies. Horm Res Paediatr 2010; 74: 267-274.

42 Bjorntorp P. Effects of age, sex, and clinical conditions on adipose tissue cellularity in man. Metabolism 1974; 23: 1091-1102.

(C) (i) $\Theta$ This work is licensed under a Creative Commons Attributioncc) NonCommercial-NoDerivs 4.0 International License. The images or other third party material in this article are included in the article's Creative Commons license, unless indicated otherwise in the credit line; if the material is not included under the Creative Commons license, users will need to obtain permission from the license holder to reproduce the material. To view a copy of this license, visit http:// creativecommons.org/licenses/by-nc-nd/4.0/

Supplementary Information accompanies this paper on International Journal of Obesity website (http://www.nature.com/ijo) 